\title{
A study on referral of patients in department of Psychiatry at Lumbini Medical College and Teaching Hospital
}

\author{
Ram Prasad Lamichhane*1, Bhaskar Sharma ${ }^{1}$, Prakash Neupane ${ }^{1}$, \\ Nisha Bhattarai ${ }^{1}$, Sandipa Sharma ${ }^{1}$
}

Department of Psychiatry, Lumbini Medical College and Teaching Hospital, Palpa, Nepal

\begin{abstract}
Introduction: In a developing country like Nepal, where there is inadequate awareness but more social stigma towards psychiatric illnesses among people, there is an important role of referral psychiatry. Referral psychiatry has been considered to be an interface between psychiatric and non-psychiatric medicines as practiced in general hospital settings. This study analyses the psychiatric problems among patient referred to psychiatry department from other outpatient departments and emergency department in a tertiary care centre. Methods: This was a descriptive hospital-based study conducted among patients who were referred to psychiatry department from different outpatient departments of Lumbini Medical College and Teaching Hospital from November 1, 2019 to April 30, 2020. Ethical issues were considered strictly. Data were entered into Statistical Package for the Social Sciences version 21.0 and descriptive analysis was done. Results: A total of 781 patients were referred out of which more than half $(n=487,62.35 \%)$ were females and the most common age group was 41 to 50 years $(n=175,22.4 \%)$. Majority of patients $(n=284,36.4 \%)$ were referred from medicine department. The most common psychiatric illness diagnosed were those included under International Classification of Diseases 10th Revision F40-48 (Anxiety, Dissociative, Stress-related, Somatoform and other Non-Psychotic Mental Disorders). Conclusions: Referral psychiatry plays an important role to diagnose the undiagnosed psychiatric illnesses earlier and better and manage accordingly so it should be prioritized and practiced in health centers.
\end{abstract}

Keywords: Psychiatric illnesses, referral psychiatry, tertiary care centre.

\section{*Correspondence:}

Dr. Ram Prasad Lamichhane

MBBS, MD (Psychiatry)

Lumbini Medical College and Teaching

Hospital, Palpa, Nepal

Email: ram26203@gmail.com

Submitted: May 5, 2021

Accepted: December 5, 2021

To cite: Lamichhane RP, Sharma B, Neupane P, Bhattarai N, Sharma S. A study on referral of patients in department of Psychiatry at Lumbini Medical College and Teaching Hospital. JGMC Nepal. 2021;14(2):107-110. DOI: $10.3126 /$ jgmcn.v14i2.40021

\section{INTRODUCTION}

World Health Organization (WHO) defines health as a state of complete physical, mental, social well being and not merely the absence of disease or infirmity. The last two dimensions fall under the umbrella of psychiatry. Being a country with literacy rate of only $67.91 \%$, there is lack of awareness regarding mental illness among people. Mental health contributes to 4 out of 10 health conditions related to Disability adjusted life years (DALYs) ${ }^{1,2}$ But in developing countries, around $75 \%$ of people battling mental health receive no treatment. $^{3}$

The patients with psychiatric disorders give much priority to physical symptoms and end up visiting general physicians rather than a psychiatrist. ${ }^{4-7}$ The referral rates of psychiatric patients vary up to 25 fold amongst practitioners ${ }^{8}$ with inpatients being referred more often than outpatients with overall referral rate of $0.3 \%{ }^{4}$ Most of the cases $(74.4 \%)$ were referred by the general physicians. ${ }^{2,8}$ The commonest reasons for referral were having unexplained physical 
symptoms in patients. ${ }^{4,9}$ Mostly male patients were referred, with age of 16 to 45 years and the psychiatric component is most frequently neurosis, stress related and somatoform disorders (45 to $51 \%$ ). ${ }^{9-11}$

The establishment of Psychiatry units in general hospitals have provided opportunities for detection of cases because of easier access to patient and lesser stigma. ${ }^{12}$ The objective of this study was to study the referral patterns of psychiatric patients, via out-patient department (OPD) in the psychiatry department of Lumbini Medical College Teaching Hospital (LMCTH), located in a hilly region with limited resources and having remarkably questionable levels of knowledge regarding the psychiatric illnesses.

\section{METHODS}

A retrospective hospital-based study was conducted in LMCTH based on number of patients who were referred to department of psychiatry from emergency department \& various outpatients departments. The study was conducted among 781 patients from November 1, 2019 to April 30,2020 . All those patients referred to psychiatry OPD were included in the study and their detail information including demography, source of referral, diagnosis arrived at the department of psychiatry were noted. Ethical issues were maintained strictly. International Classification of Diseases $10^{\text {th }}$ Revision (ICD 10) was used by the consultant psychiatrists to evaluate the patients and diagnosis was made. Then, the collected data was entered in Statistical Package for the Social Sciences software version 21.0 and results were analyzed and interpreted.

\section{RESULTS}

Out of 781 patients included in the study, majority were females $(n=487,62.35 \%)$. Majority of patients were referred from department of medicine $(n=284,36.4 \%)$ \& emergency department $(n=258,33 \%)$ followed by otorhinolaryngology, orthopedics, gynecology and obstetrics, surgery, pediatrics, dermatology, dental and ophthalmology (Table 1)

Table 1: Referral Departments

\begin{tabular}{lcc}
\hline & Number & Percentage \\
Dental & 6 & 0.8 \\
Dermatology & 14 & 1.8 \\
Emergency & 258 & 33.0 \\
Otorhinolaryngology & 93 & 11.9 \\
Gynaecology /Obstetrics & 35 & 4.5 \\
Medicine & 284 & 36.4 \\
Ophthalmology & 5 & 0.6 \\
Orthopaedics & 42 & 5.4 \\
Paediatrics & 15 & 1.9 \\
Surgery & 29 & 3.7 \\
Total & 781 & 100.0 \\
\hline
\end{tabular}

Most common psychiatric illness diagnosed among the referred cases were those included under ICD 10 F40-48 (Anxiety, Dissociative, Stress-related, Somatoform and other Non-Psychotic Mental Disorders) (Table 2).

Table 2: ICD-10 code

\begin{tabular}{lcc}
\hline & Number & Percentage \\
F00-09 & 14 & 1.8 \\
F10-19 & 132 & 16.9 \\
F20-29 & 27 & 3.5 \\
F30-39 & 104 & 13.3 \\
F40-48 & 369 & 47.2 \\
F50-59 & 21 & 2.7 \\
F70 & 3 & 0.4 \\
F90-98 & 1 & 0.1 \\
F99 & 54 & 6.9 \\
G40 code & 12 & 1.5 \\
G43 code & 13 & 1.7 \\
G44 code & 26 & 3.3 \\
R55 & 1 & 0.1 \\
X60-84 & 4 & 0.5 \\
\hline
\end{tabular}

Based on geographical distribution, majority of patients were from Palpa district $(n=560,71.7 \%)$ followed by Syangja $(n=78,10 \%)$ (Table 3$)$.

Table 3: Geographical distribution

\begin{tabular}{lcc}
\hline District & Number & Percentage \\
Argakhanchi & 31 & 3.9 \\
Baglung & 18 & 2.3 \\
Gorkha & 1 & 0.1 \\
Gulmi & 72 & 9.2 \\
Kapilbastu & 8 & 1.0 \\
Kathmandu & 1 & 0.1 \\
Palpa & 560 & 71.7 \\
Parbat & 4 & 0.5 \\
Rupandehi & 6 & 0.7 \\
Siraha & 1 & 0.1 \\
Syangja & 78 & 10.0 \\
Tanahun & 1 & 0.1 \\
\hline
\end{tabular}

Study also shows majority of patients were between the age group of 41 to 50 years $(n=175,22.4 \%)$ (Table 4$)$

Table 4. Age-distribution of the patients

\begin{tabular}{lcc}
\hline Age group & Frequency & Percentage \\
0 to 10 & 9 & 1.2 \\
11 to 20 & 86 & 11.0 \\
21 to 30 & 128 & 16.4 \\
31 to 40 & 169 & 21.6 \\
41 to 50 & 175 & 22.4 \\
51 to 60 & 104 & 13.3 \\
61 to 70 & 72 & 9.2 \\
71 to 80 & 27 & 3.5 \\
$>80$ & 11 & 1.4 \\
\hline
\end{tabular}

\section{DISCUSSION}

Study shows majority of patients referred to psychiatry OPD were from medicine OPD which is consistent to other 
studies. ${ }^{13-15}$ This may be due to multiple reasons, one of them being increased number of patients visiting medicine OPD. Also, it is estimated that 21 to $26 \%$ of medical outpatient have psychiatric disorder and lifetime prevalence of mental disorder in chronically physically ill patient is around $42 \%$ compared to $33 \%$ who did not have long term physical disability. ${ }^{16}$ As a developing nation, majority of patients are not adequately aware about psychiatric illness as well as due to existing social stigma people cannot seek psychiatric consultation at first instance \& are only referred once they visit physician in medicine department.

About 33\% patients were referred from emergency department to department of psychiatry as large proportion of patients with Alcohol related disorders landing up in emergency can be the major contributor to this number.

Among the referred patients, the most common diagnosis falls under the spectrum of ICD 10 F40-48(Anxiety, dissociative, stress-related, somatoform and other nonpsychotic mental disorders). Similar findings have been reported by other studies. ${ }^{17-19}$

Majority of patients in the study were females. This shows that females are also being more concerned about their health and come to seek treatment; the reason may be the increasing literacy rate and awareness among people. Study done by Kumar et al. ${ }^{17}$ also reported the similar finding.

Majority of patients were among the age group 41 to 50 years, $(n=175,22.4 \%)$, the result is similar to study conducted by Brown et al. ${ }^{20}$ This can be supported with the fact that adults are more prone to physical \& mental stress due to due to their active lifestyle, familial \& social responsibilities, and most of the people from this age group are financially independent to seek health facilities by them.

\section{CONCLUSIONS}

This study concludes that referral psychiatry should be practised as far as possible in general hospital settings, so that the undiagnosed psychiatric illnesses among patients could be diagnosed and treated accordingly, especially in a developing country where such illnesses are still stigmatized and less prioritized.

CONFLICTS OF INTEREST: None declared

\section{SOURCE OF FUNDING: None}

\section{REFERENCES}

1. Sultan-E-Monzur M, Maruf MM, Roy S, Royle RKS, Rahman MS. Pattern of psychiatric morbidity among patients attended at psychiatry outpatient department in a private medical college hospital. Bang J Psychiatry 2016;30(1):10-13. DOI:10.3329/bjpsy.v30i1.37856

2. Murthy RS. Mental health programme in the $11^{\text {th }}$ five year plan. Ind J Med Res. 2007;125(6):707-11. PMID: 17704544.

3. Becker AE, Kleinman A. Mental health and the global agenda; N Engl J med. 2013;369(1) 66-73. DOI: 10.1056/NEJMra1110827 PMID: 23822778.

4. al-Ansari EA, el-Hilu S, el-Hihi MA, Hassan KI. Patterns of psychiatric consultations in Kuwait general hospitals. Gen Hosp Psychiatry. 1990;12(4):257-63. DOI: 10.1016/0163-8343(90)90064-J PMID: 2376326.

5. Leepa V, Rajan S. Psychiatric Referral Pattern in a General Hospital. 2018MJPAHS. 2018; 1(1):28-31. DOI: 10.3126/mjpahs.v1i1.22456

6. Doongaji DR, Nadkarni RP, Bhatawdekar ML. Psychiatric referrals in two general hospitals. J Postgrad Med. 1989;35:171-7. PMID: 0002634758.

7. Grover S, Sahoo S, Aggarwal S, Dhiman S, Chakrabarti $\mathrm{S}$, Avasthi A. Reasons for referral and diagnostic concordance between physicians/surgeons and the consultation-liaison psychiatry team: An exploratory study from a tertiary care hospital in India. Indian J Psychiatry. 2017;59(2):170-175. DOI: 10.4103/ psychiatry.IndianJPsychiatry_305_16 PMID: 28827863.

8. Melzer D, Watters L, Paykel E, Singh K, Gormley N. Factors explaining the use of psychiatric services by general practices. Br J Gen Pract. 1999;49(448):88791. PMID: 10818654.

9. Bhogale GS, Katte RM, Heble SP, Sinha UK, Patil BA. Psychiatric referrals in multispeciality hospital. Indian J Psychiatry. 2000;42(2):188-94. PMID: 21407934.

10. Dhavale HS, Barve RG. Psychiatric referral pattern in general hospital. J Postgrad Med. 1990;36(4):199-202. PMID: 2132244.

11. Shrestha MR, Pradhan S, Sharma S. Morbidity Pattern of Psychiatric Disorders in Patient Seeking Treatment in Psychiatric OPD of Private Tertiary Care Hospital. Available from: https://citeseerx.ist.psu.edu/viewdoc/ download?doi=10.1.1.993.1876\&rep=rep1\&type=pdf

12. Shakya DR, Pandey AK, Shyangwa PM, et al. Psychiatric morbidity profiles of referred psychiatry OPD 
patients in a general hospital. Indian Medical Journal 2009;103(12):407-11.

13. Dhavale HS, Barve RG, Psychiatric Referral Pattern in General Hospital. Journal of postgraduate medicine.1990;36(4) 192-202. PMID: 2132244.

14. Malik M, Abbas N, Azad N. Psychiatric Morbidity in Medical and Surgical in Patients, Referred for Psychiatric Consultation. Journal of Rawalpindi Medical College 2008;12. Available from: http://www. journalrmc.com/index.php/JRMC/article/view/757

15. Jhanjee A, Kumar P, Srivastav S, Bhatia M.S. A Descriptive Study of Referral Pattern in Department of Psychiatry of A Tertiary Care Hospital of North India. Delhi Psychiatric Journal 2011;14 (1) 92-4.

16. Singh PM, Vaidya L, Shrestha DM, Tajhya R, Shakya S. Consultation liaison psychiatry at Nepal Medical College and Teaching Hospital. Nepal Med Coll J. 2009;11(4):272-274. PMID: 20635608.

17. Kumar GS, Reddy KVR, Anushanemani. Inpatient psychiatric referrals to general hospital psychiatry unit in a tertiary care hospital in Andhra Pradesh. Journal of Dental and Medical Sciences. 2015;14(1):26-29. DOI: $10.9790 / 0853$

18. Keertish N, Sathyanarayana MT, Hemanth Kumar BG, Singh N, Udagave K. J Clin Diagn Res. 2013;7(8):168991. DOI: 10.7860/JCDR/2013/6425.3238 PMID: 24086876.

19. Huyse FJ, Herzog T, Lobo A, Malt UF, Opmeer BC, Stein B et al. Consultation-Liaison psychiatric service delivery results from a European study. General Hospital Psychiatry.2001;23:24-32. DOI: 10.1016/ S0163-8343(01)00139-6 PMID: 11427244.

20. Jindal RC, Hemrajani DK. A study of psychiatric referrals in a general hospital. Indian J Psychiatry. 1980;22(1):108-10. PMID: 22058450.

21. Brown A, Cooper AF. The Impact of a Liaison Psychiatry Service on Patterns of Referral in a General Hospital. British Journal of Psychiatry 1987;150:83-87 DOI: 10.1192/bjp.150.1.83 PMID: 3651738. 